\title{
The Adult Mouse Subependymal Zone Regenerates Efficiently in the Absence of Tenascin-C
}

\author{
Ilias Kazanis, ${ }^{1}$ Aisha Belhadi, ${ }^{1}$ Andreas Faissner, ${ }^{2}$ and Charles ffrench-Constant ${ }^{1}$ \\ ${ }^{1}$ Department of Pathology, University of Cambridge, Cambridge CB2 1QP, United Kingdom, and ${ }^{2}$ Department of Cell Morphology and Molecular \\ Neurobiology, Ruhr-University, D-44780 Bochum, Germany
}

\begin{abstract}
The subependymal zone (SEZ) of the lateral ventricles of the adult mouse brain hosts neurogenesis from a neural stem cell population with the morphology of astrocytes (termed type-B cells). Tenascin-C is a large extracellular matrix glycoprotein present in the SEZ that has been shown to regulate the development of embryonic neural stem cells and the proliferation and migration of early postnatal neural precursors. Here we show that tenascin-C is produced by type-B cells and forms a layer between SEZ and the adjacent striatum. Tenascin-C deficiency resulted in minor structural differences in and around the SEZ. However, the numbers of neural stem cells and their progeny remained unaffected, as did their regeneration after depletion of mitotic cells using the antimitotic drug cytosine- $\beta$-Darabinofuranoside. Our results reveal a remarkable ability of the adult neural stem cell niche to retain proper function even after the removal of major extracellular matrix molecules.
\end{abstract}

Key words: tenascin-C; extracellular matrix; adult neurogenesis; subependymal zone; stem cell; niche

\section{Introduction}

Over the last decade, experimental studies have shown that a restricted neuroregenerative capacity remains within two areas of the adult mammalian telencephalon: the subependymal zone (SEZ) of the lateral ventricles (LVs) and the subgranular layer of the hippocampus. Cells from the SEZ have been shown to generate neurons and glia in vitro (Gritti et al., 1996; Johe et al., 1996) as well as in vivo (Lois et al., 1996; Hack et al., 2005). Previously, it has been proposed (Doetsch, 2003; Riquelme et al., 2008) that these neurogenic areas have the characteristics of stem cell niches based on observations regarding their cytoarchitecture (Doetsch et al., 1997) and their extracellular matrix (ECM) composition (Mercier et al., 2003; Kerever et al., 2007). Stem cell niches provide a sheltering environment from differentiation and apoptotic stimuli and ensure the production of new differentiated cells over the life span of the organism (Moore and Lemischka, 2006). Within the SEZ the neural stem cells (type-B cells) are identified as GFAP-immunopositive astrocytes, giving rise to type- $\mathrm{C}$ transit amplifying precursors ( $\mathrm{TaPs}$ ) that finally produce type-A cells (neuroblasts) (Doetsch et al., 1999b). TaPs are Mash1-positive (Parras et al., 2004) with a subpopulation also Olig2-positive (Menn et al., 2006), whereas neuroblasts are polysialylated neural cell adhesion molecule (PSA-NCAM)-positive.

\footnotetext{
Received July 19, 2007; revised 0ct. 26, 2007; accepted Nov. 5, 2007.

This work was supported by the Biotechnology and Biological Sciences Research Council, UK, and by the National Institutes of Health-National Institute of Biomedical Imaging and Bioengineering Quantum Grant Project 1P20EB00706. We thank Dr. Francois Guillemot (National Institute for Medical Research, London, UK) for the kind gift of the Mash1 antibody and Dr. Fiona Doetsch (Columbia University, New York, NY) for advice on the AraC protocol.

Correspondence should be addressed to llias Kazanis, Department of Pathology, University of Cambridge, Cambridge CB2 1QP, UK. E-mail: ik255@cam.ac.uk.

DOI:10.1523/JNEUROSCI.3279-07.2007

Copyright $\odot 2007$ Society for Neuroscience $\quad$ 0270-6474/07/2713991-06\$15.00/0
}

Tenascin-C $(\mathrm{TnC})$ is a large ECM glycoprotein (Jones and Jones, 2000) that is expressed in the brain neurogenic zones during development (Steindler et al., 1995; Garcion et al., 2004) and postnatally (Thomas et al., 1996; Garcion et al., 2001; Peretto et al., 2005; Bonnert et al., 2006; de Chevigny et al., 2006) as well as in areas of plasticity (i.e., after injury) in the adult brain (Laywell et al., 1992; Gates et al., 1996; Nishio et al., 2005). This expression profile combined with results using $\mathrm{TnC}$ null mice showing a role for $\mathrm{TnC}$ in the proliferation and migration of early postnatal neural precursors (Garcion et al., 2001) and the growth-factor responsiveness of embryonic neural stem cells (NSC) (Garcion et al., 2004) led us to ask whether $\mathrm{TnC}$ also plays a role in adult neurogenesis.

\section{Materials and Methods}

Animals and treatments. Adult (3-5 months old) heterozygous (control) and homozygous (null) mice in the 129sv background were derived from a transgenic mouse with a LacZ cassette knocked into the $T n C$ gene to create a null allele (Saga et al., 1992). The protocol using the antimitotic drug cytosine- $\beta$-D-arabinofuranoside (AraC) to deplete type-C and type-A cells was modified from Doetsch et al. (1999b) as described in supplementary material (available at www.jneurosci.org as supplemental material). Animals were killed after the end of the infusion (day 0), or after 2, 4, or $6 \mathrm{~d}$ ( $n=3 / 4$ per genotype per time point). For cumulative bromodeoxyuridine (BrdU) labeling, mice received two intraperitoneal injections per day ( $50 \mathrm{mg} / \mathrm{kg}$, b.w.; Sigma, St. Louis, MO) for $2 \mathrm{~d}$ and were killed $1 \mathrm{~h}$ after the last injection ( $n=2$ per genotype). To identify slowdividing, label-retaining NSCs, animals ( $n=3$ per genotype) received 2 BrdU injections per day for $3 \mathrm{~d}$ and were killed 3 weeks later.

Immunohistochemistry. Animals were perfused transcardially with $2 \%$ paraformaldehyde, after which brains were postfixed ( $2 \mathrm{~h})$, cryoprotected, and frozen. For immunostaining and bromodeoxyuridine (BrdU) and 5-bromo-4-chloro-3-indolyl- $\beta$-D-galactopyranoside (Xgal) staining, $14 \mu \mathrm{m}$ sections were processed as described in the supplementary material (available at www.jneurosci.org). Statistical comparisons 

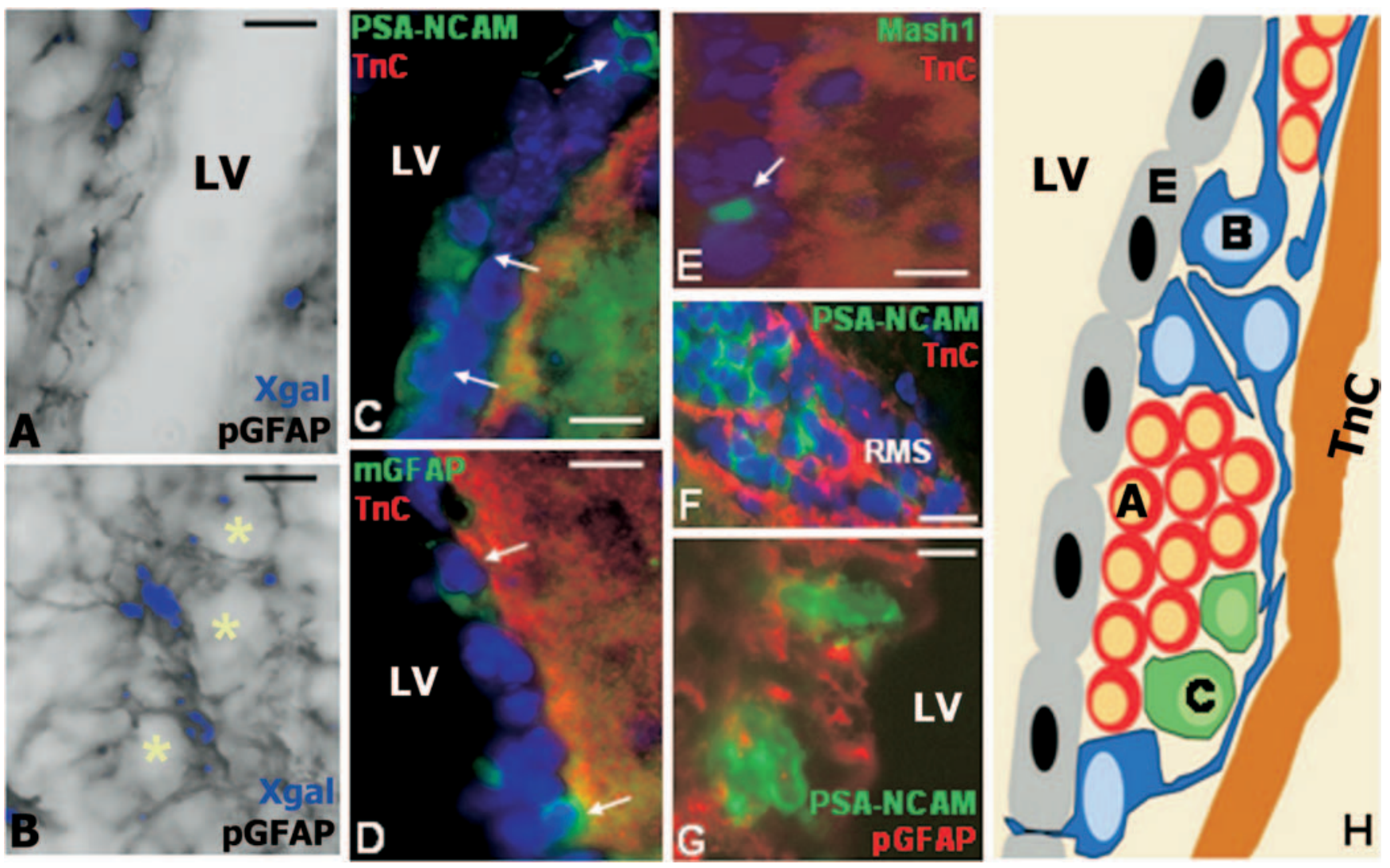

$\mathrm{H}$

Figure 1. TnC expression in the SEZ. A, B, Xgal staining (blue pseudocolor) and GFAP immunohistochemistry colabeling in the SEZ and RMS (asterisks indicate Xgal/GFAP-negative neuroblast clusters). $\mathbf{C}-\boldsymbol{G}$, Double immunolabeling of TnC with different cell markers in the SEZ ( $\mathbf{C}-\boldsymbol{E}, \boldsymbol{G})$ and the RMS (F). Arrows indicate PSA-NCAM, GFAP (monoclonal antibody) and Mash1-positive cells. A representative image of PSA-NCAM-positive clusters contained within GFAP-positive tubes is shown in $\boldsymbol{G}$. The positioning of the different cell types relative to the TnC immunopositive zone is summarized in $(\boldsymbol{H})$. Scale bars: $15 \mu \mathrm{m}$.

used Student's $t$ test (non-treated TnC heterozygous vs null animals) or two-way ANOVA (AraC treatment) with genotype and time as independent variables, followed by the Scheffe post hoc test using SSPS 11.5 (SPSS, Chicago, IL) or GraphPad (San Diego, CA) Prism.

In vitro assays. Passage 2 and 5 neurospheres were derived from adult $\mathrm{TnC}+/-$ and $-/-\mathrm{SEZ}$; all experiments were repeated three times and, in each experiment, two animals per genotype were pooled. Neurospheres were cultured in the presence of $100 \mathrm{~nm} \mathrm{AraC}\left(\mathrm{LC}_{50}\right.$ as calculated by chemosensitivity assays) for $4 \mathrm{~d}$. Subsequently, they were dissociated and plated at clonal density $(\sim 1 \mathrm{cell} / 10 \mu \mathrm{l})$. For pulse experiments BrdU was added to the medium for 3 or $48 \mathrm{~h}$. For time-lapse experiments, cells were monitored for $3 \mathrm{~d}$, with images taken every 20-30 min using a Nikon (Tokyo, Japan) Diaphot inverted microscope. Image processing was done with Simple PCl 6 software (Compix, Irvine, CA).

\section{Results}

\section{TnC deficiency results in structural differences around} the LVs

First, we examined the source and localization of TnC in the SEZ, taking advantage of a lac $Z$ cassette encoding $\beta$-galactosidase in the null allele of TnC heterozygous mice (Saga et al., 1992) to identify cells expressing TnC. Xgal histochemistry in combination with GFAP immunostaining revealed that $\mathrm{TnC}$ was produced by astrocytes both at the SEZ [a population which includes the type-B NSC (Doetsch et al., 1999a)] and the RMS (Fig. 1 A,B). Furthermore, TnC immunoreactivity was restricted to a layer underlying the SEZ, delineating its borders with the striatum. Double labeling with markers of the different cell types that constitute the SEZ (Fig. 1) revealed that TnC immunoreactivity did not strictly co-localize with either the PSA-NCAM-positive neu- roblasts, or the Mash1-positive transit amplifying precursors. The GFAP + cells in the SEZ, with their more complex shape and numerous processes were the cells more frequently touching the $\mathrm{TnC}$ positive layer, though with cell bodies mostly situated of the ventricular side of the layer (Fig. $1 D, H$ ). At the anterior LV horns the clusters of neuroblasts that were aggregating to form the RMS were surrounded by a TnC rich ECM (Fig. $1 F$ ).

Next, we compared the structure and cellular composition of the SEZ in mice heterozygous and homozygous for the TnC null allele to investigate a possible role of $\mathrm{TnC}$ in adult neurogenesis. Although the cytoarchitecture of the LV walls was similar in both genotypes, two structural differences were detected. First, within the SEZ, the number of neuroblast clusters along the LV was significantly increased in the TnC null animals (2.6 clusters/LV in the $\mathrm{TnC}+/-; 3.7$ clusters/LV in the TnC-/-;p<0.002). The structure of the clusters was identical to that of the heterozygotes, with GFAP+ cells forming tubes surrounding type-A cells (Fig. 1G). Second, in the TnC null animals a cell-free zone appeared at the lateral septal nuclei (LSN) at the proximity to the LV wall, below the ependymal and GFAP-rich layer (Fig. 2A, B, supplemental Fig. 1, available at www.jneurosci.org as supplemental material). No differences were detected in the numbers of the ependymal, Mash1- or Olig2-positive cells as well as in the total GFAP and PSA-NCAM immunoreactivity (data not shown). Moreover, the proliferative activity of the SEZ was found to be similar between TnC heterozygote and null mice, as assessed by both phosphohistone 3 and proliferating cell nuclear antigen (PCNA) immunostainings (supplemental Fig. 2, available at www. jneurosci.org as supplemental material) (data not shown). 
$\mathrm{TnC}+/-$
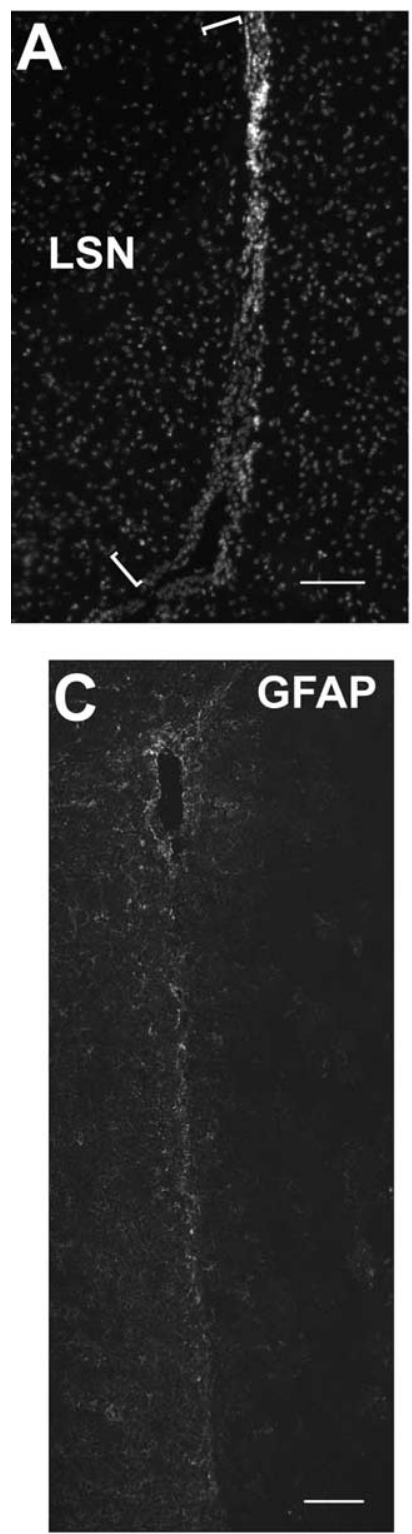

TnC-/-
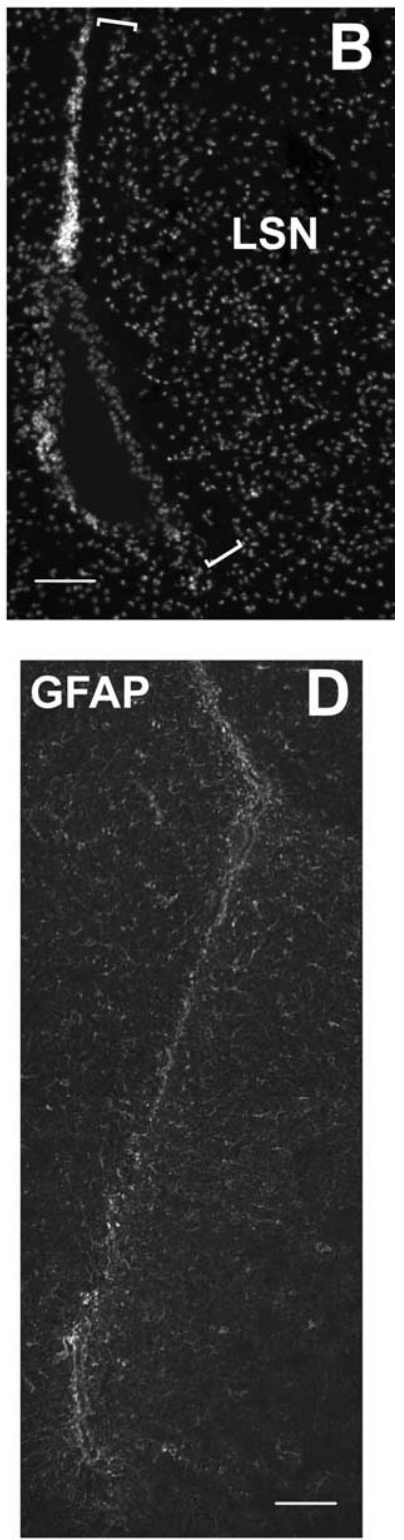

Figure 2. $A, B$, Representative images of the LSN area proximal to the LV (indicated by the brackets) from $\mathrm{TnC}+/-$ and $\mathrm{TnC}-/-$ mice, using Hoecsht staining to label nuclei. $\boldsymbol{C}, \boldsymbol{D}$, Characteristic GFAP immunostaining on day 0 in the LV area of TnC heterozygous ( $C$ and null (D) mice. Scale bars: $100 \mu \mathrm{m}$.

Because the newborn neurons of the SEZ migrate to the olfactory bulb, an additional analysis of neurogenesis was performed by comparing $\mathrm{TnC}+/-$ and $-/-$ olfactory bulbs. The histology and the numbers of Dcx-positive migrating neurons were similar in both genotypes (supplemental Fig. 3, available at www.jneurosci.org as supplemental material). Moreover, no differences were found in the number of TH-positive (GABAergic) or calretininpositive (non-GABAergic) periglomerular interneurons (Kosaka et al., 1998) in the TnC-/- mice (supplemental Fig. 3, available at www.jneurosci.org as supplemental material).

\section{Neural stem cell numbers and proliferation are unaffected by} a lack of TnC

Because the astrocytes that include the type-B NSC were the major source of $\mathrm{TnC}$ in the SEZ, and the only cells consistently in contact with the extracellular TnC-rich layer, we assessed whether they were affected by the absence of TnC. To evaluate their numbers we took advantage of their relative quiescence (Doetsch et al., 1999a) and used a BrdU retention protocol. Heterozygous or null mice were injected with BrdU twice a day for $3 \mathrm{~d}$ and were killed 3 weeks after the last injection, by which time all TaPs or neuroblasts would have either diluted BrdU or migrated away from the LVs. Few labeled (i.e., slowly dividing) cells could be detected in the SEZ and there were no differences in numbers or positioning between the TnC null and heterozygous animals (data not shown). As an alternative method of comparing the numbers of type-B NSCs between $\mathrm{TnC}+/-$ and $-/-$ mice we dissected the SEZs from adult mice and quantified the generation of neurospheres, many of which are derived from type-B cells. Once again, the results were similar in both genotypes (4.5 spheres/100 TnC+/- cells compared with 4.1 spheres/100 $\mathrm{TnC}-/-$ cells).

To gain a better insight in the mitotic activity of NSC we also used the neurosphere assay, as neurosphere growth has been shown to retain characteristics of the in vivo neurogenic process (Parras et al., 2004). TnC is highly expressed in neurospheres (Garcion et al., 2004) and after their dissociation it remains bound on the surface of the cells (our unpublished observation). SEZ-derived neurospheres from $\mathrm{TnC}+/-$ and $-/-$ mice were treated with AraC (100 nM) for $4 \mathrm{~d}$. We reasoned that this would select for slowly dividing NSC at the expense of rapidly dividing $\mathrm{TaP}$ and neuroblast populations. Subsequently, spheres were dissociated, cells were plated in clonal density and pulsed with BrdU for 3 or $48 \mathrm{~h}$. The percentage of BrdU-labeled cells was the same in both genotypes either after the short or the cumulative pulse (supplemental Fig. 4, available at www.jneurosci.org as supplemental material). To distinguish the first divisions of the selected population from those of their progeny, we monitored single cells for $3 \mathrm{~d}$ after the removal of AraC by time-lapse imaging. Similar numbers of cells underwent their first mitosis within the first $3 \mathrm{~d}$ after the removal of AraC in both genotypes, with 34 and $30 \%$ of the TnC heterozygous and null cells, respectively, dividing over the first $24 \mathrm{~h}$.

\section{Efficient SEZ regeneration in the absence of TnC}

One of the fundamental properties of the SEZ is its ability to regenerate after the depletion of the TaP (type $\mathrm{C}$ cells) and neuroblasts (type-A cells) through the divisions of the surviving type-B stem cells. Therefore, to assess stem and progenitor cell properties in the absence of $\mathrm{TnC}$ we used AraC to ablate in vivo type- $\mathrm{C}$ and type-A cells. AraC infusion resulted in a marked depletion of type-A cells as well as of Mash1 or Olig2-positive TaPs in the SEZ of both TnC heterozygous and null mice. This was followed by efficient regeneration in the same time-frame in both genotypes (Fig. 3, supplemental Fig. 2, available at www.jneurosci. org as supplemental material) (note that high numbers of Olig2positive cells survived the treatment, as expected by the expression of Olig2 in postmitotic oligodendroglia). TaP cells reached their normal, pretreatment levels by $6 \mathrm{~d}$. PSA-NCAM-positive type-A cells were practically undetectable until $2 \mathrm{~d}$, reappeared at $4 \mathrm{~d}$ and exceeded the $40 \%$ of their normal levels in both genotypes by $6 \mathrm{~d}$. The overall mitotic activity of the SEZ, as assessed by PCNA immunostaining, increased similarly in $\mathrm{TnC}+/-$ and $\mathrm{TnC}-/-$ mice up to $6 \mathrm{~d}$ when it reached pretreatment levels (Fig. 3). Double immunostainings revealed that the fraction of Olig2 cycling cells during regeneration was similar in both genotypes (supplemental Fig. 2, available at www.jneurosci.org as supplemental material) 


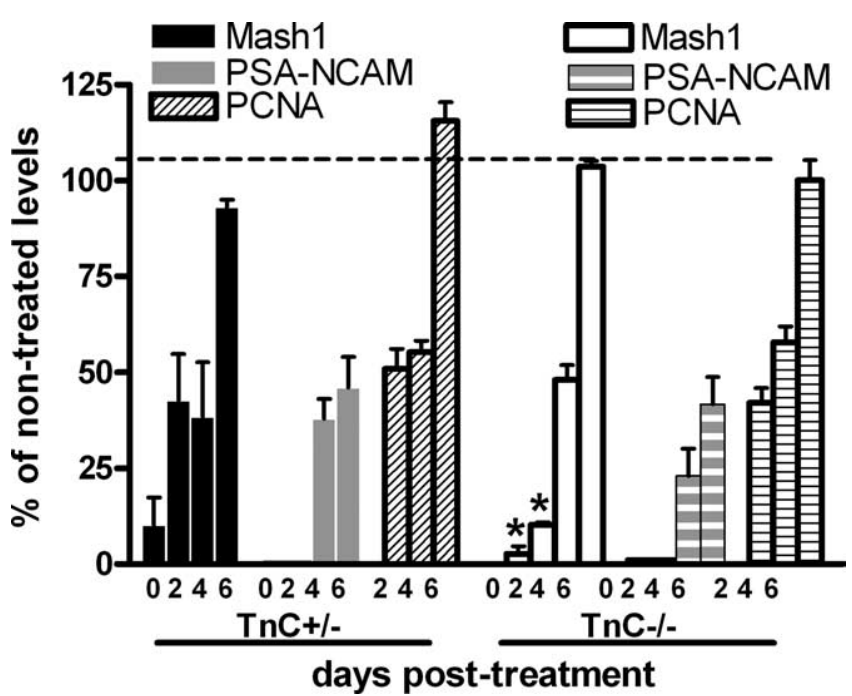

Figure 3. Graph showing the numbers of type-C and type-A cells, as well as of PCNA-positive mitotic cells, in the infused hemisphere of TnC heterozygous and null mice after AraC treatment. The numbers are expressed as percentages of the pretreatment values. ${ }^{*} p<0.05$, compared with the respective $\mathrm{InC}+/-$ levels. Error bars indicate SD.

Although the TnC deficient SEZ regenerated efficiently after AraC infusion, some differences were observed between genotypes. By the end of the antimitotic treatment, GFAP (detected with both the monoclonal and the polyclonal antibody) was increased in the area surrounding the LVs, with the increase being significantly higher in the TnC-/- mice (Fig. $2 C, D$ ). GFAP immunostaining gradually decreased to pretreatment levels by $6 \mathrm{~d}$ with the difference between the two genotypes not evident from $2 \mathrm{~d}$ onward (data not shown). In addition, although AraC infusion resulted in a higher than $90 \%$ depletion of Mash1-positive cells in both genotypes, in the TnC deficient SEZ the ablation was more efficient $(97 \%$ reduction in the TaP numbers compared with $91 \%$ in the heterozygotes; $p<0.05$ ) (Fig. 3).

\section{Discussion}

Our expression data confirmed the production and high expression of TnC by SEZ astrocytes (Fig. 1). Although expression of $\mathrm{TnC}$ bordering areas of dynamic cell movements and interactions has been well documented during development (Steindler et al., 1995) and after injury (Laywell et al., 1992; Gates et al., 1996; Nishio et al., 2005), its role remains elusive (Nishio et al., 2005). The only difference we detected within the SEZ of the TnC deficient mice was the increased number of type-A cell clusters along the LV wall. In the early postnatal SEZ the migrating neuroblasts are ensheathed by TnC-rich ECM layers rather than glial processes (Peretto et al., 2005). During this transitional stage, a mediolateral gradient of $\mathrm{TnC}$ has been described and the formation of glial tubes proceeds more efficiently in the $\mathrm{TnC}$-poor area (Peretto et al., 2005). Therefore, it is possible that the absence of any restrictive effect of this ECM in the TnC deficient mice might lead to the formation of a more complex glial-tube network. A previous study by de Chevigny et al. (2006) failed to detect any differences in the neuroblast chains in the brain of adult TnC null mice, but their assessment was qualitative rather than quantitative. The observed lower cell density in the LSN of the TnC null mice might also reflect developmental changes because $\mathrm{TnC}$ is expressed by neural progenitors of the septal primordia and has been shown to control growth factor responsiveness and differentiation properties (Garcion et al., 2004) (our unpublished ob- servation). The LSN are rich in GABAergic neurons and contain significant numbers of the parvalbumin-positive subtype (Hartig et al., 1995; Brauer et al., 1999) that was the only neuronal type found to be significantly decreased in the cortex of the TnC null mice (Irintchev et al., 2005).

To further investigate the SEZ and more specifically the properties of TnC deficient type-B stem cells we used the antimitotic drug AraC. In the absence of $\mathrm{TnC}$, regeneration of the SEZ occurred efficiently and within the same time-frame as in the heterozygous mice. One difference was the increased activation of astrocytes after the AraC treatment. This is consistent with previous reports of increased recruitment of astroglia around CNS wounds in TnC null mice (Steindler et al., 1995) and it will be interesting to investigate the contribution of astrocyte activation to SEZ homeostasis. Astrocytes have been shown to support neurogenesis (Lim and Alvarez-Buylla, 1999), but in cases of injury, reactive astroglia have been shown both to impede (Bahr et al., 1995) and to facilitate (Iseda et al., 2003) tissue regeneration.

The regeneration experiment also suggested there might be a difference in the behavior of the TnC-deficient TaP population, because their increased depletion did not result in any delay in their final regeneration (Fig. 3, supplemental Fig. 2, available at www.jneurosci.org as supplemental material). However, a computational approach to model the different cell population kinetics during the first stages of regeneration shows that no such differences are required to explain the observed results. A 3 d SEZ regeneration simulation was constructed (see supplemental Methods and supplemental Fig. 5, available at www.jneurosci.org as supplemental material). One $\mathrm{TnC}+/-$ and one $\mathrm{TnC}-/-\mathrm{SEZ}$, assumed to contain 200 type-B and 100 type- $C$ cells each [because previous SEZ descriptions (Doetsch et al., 1999b) have shown that type-B cell numbers are approximately two times higher than the type-C cell numbers] were simulated to regenerate after AraC treatment. After AraC treatment few type- $C$ cells survive (based on our data shown in Fig. 3) and there is a slight decrease in the numbers of type-B cells (Doetsch et al., 1999b). Posttreatment type-B NSC kinetics were based on our in vitro data analyzing AraC-depleted neurosphere cells, whereas type-C cells were assumed to divide symmetrically once every $24 \mathrm{~h}$ (see also supplemental material, available at www.jneurosci.org). The model revealed that the regeneration process could be separated in two phases. During the first phase (0-1 d of the simulation) the main regenerating force is the mitotic activity of type- $\mathrm{B}$ cells and not the self-renewing divisions of the surviving TaP (Fig. 4), with almost half of the TaPs present at the end of the simulation being produced within this stage (supplemental Fig. 5, available at www.jneurosci.org as supplemental material). The second phase spans the rest of the time-period ( $1-3 \mathrm{~d}$ ) and is characterized by the increasing contribution of type- $\mathrm{C}$ cell proliferation to the regenerative process. A third phase in which type- $\mathrm{C}$ cells would divide to produce type-A cells was not modeled. Critically, when comparing TnC heterozygous and null mice the model predicts that provided that type-B cell numbers are similar in both genotypes (as suggested by our analysis of GFAP immunoreactivity, BrdU retaining experiments, and neurosphere formation assays) and their mitotic activity is similar (as suggested by the in vitro assays), type-B cell divisions will drive the massive reappearance of TaPs in both genotypes in such a way that any initial differences in the numbers of either Mash1 or Olig2-positive type-C cells is quickly decreased (phase 1) and subsequently disappears (phase 2). This will be the case even if, as we observed, there is no difference in the proliferation rate of the TaP type- $\mathrm{C}$ cells be- 

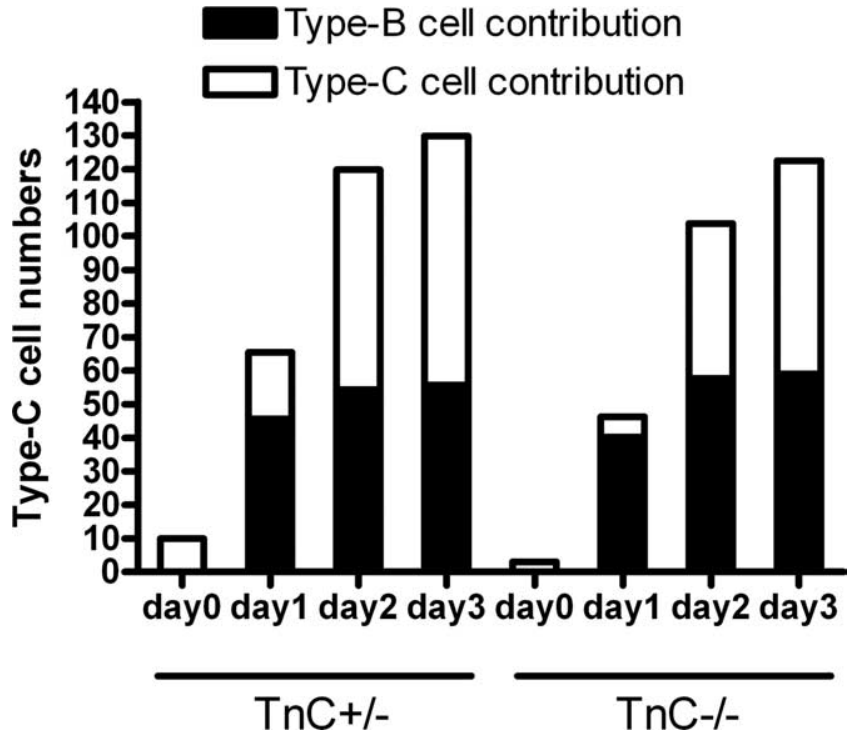

Figure 4. Graph showing the contribution of type- $B$ cell division and type-C self-renewal to the regeneration of the type- $C$ cell pool, based on the simulation model. Bars depict the total number of type-C cells, whereas the contribution of either type-B or type-C cells is illustrated by the different colors.

tween the two genotypes. (supplemental Fig. 2, available at www. jneurosci.org as supplemental material).

Although our model is valuable for the analysis of the initial phase of SEZ regeneration, a number of factors will likely limit its predictive value at later time points. These include the use of markers that may not distinguish the different cell populations with complete accuracy and the extrapolation from neurosphere cultures as to the proliferative rates of these cells in vivo. In addition, the rapid removal of $\mathrm{AraC}$ in the in vitro assays, compared with its slow in vivo clearance, and the assumption that all type- $\mathrm{B}$ cell divisions are asymmetric although previous work (Doetsch et al. 1999b) suggests that some symmetric, self-renewing divisions must occur may explain why the simulated regeneration occurs faster than in vivo. Together, these caveats emphasize the need for additional studies on the kinetics of cell behavior in the intact SEZ.

The persistence of a neurogenic niche with regenerative capacity in the adult brain suggests the existence of distinct mechanisms regulating the development and homeostasis (maintenance) of the SEZ in the embryo and adult respectively. The structural phenotype in the $\mathrm{TnC}$ deficient mice is in agreement with a specific role of this glycoprotein during development, as suggested by other studies (Garcion et al., 2004; Irintchev et al., 2005; Peretto et al., 2005). The presence of a TnC-rich layer at the border of the SEZ, in combination with the astrocyte overactivation after AraC treatment in the $\mathrm{TnC}$ null mice, also indicates a role for TnC in the homeostasis of the adult SEZ. However, despite the correlation of TnC expression with the "progenitor state" of adult SEZ cells (Bonnert et al., 2006) and in contrast to our previous work on embryonic NSC (Garcion et al., 2004), the adult NSC/progenitor population appears unaffected by the absence of TnC. One explanation could be the existence of a network of compensatory ECM molecules within the adult SEZ. Chondroitin-sulfate-containing proteoglycans are present in high concentrations in the same area (Thomas et al., 1996; von Holst et al., 2006) whereas other ECM molecules, like fibulins (Rauch et al., 2005) or other members of the tenascin family (Jones and Jones, 2000), have been suggested to be able to partly compensate for the loss of TnC. It would therefore be of interest to further investigate any compensatory upregulation of other ECM molecules in the TnC deficient SEZ. Nevertheless, our results highlight the remarkable ability of the adult brain to cope with the removal of major ECM components.

\section{References}

Bahr M, Przyrembel C, Bastmeyer M (1995) Astrocytes from adult rat optic nerves are nonpermissive for regenerating retinal ganglion cell axons. Exp Neurol 131:211-220.

Bonnert TP, Bilsland JG, Guest PC, Heavens R, McLaren D, Dale C, Thakur M, McAllister G, Munoz-Sanjuan I (2006) Molecular characterization of adult mouse subventricular zone progenitor cells during the onset of differentiation. Eur J Neurosci 24:661-675.

Brauer K, Holzer M, Bruckner G, Tremere L, Rasmusson DD, Poethke R, Arendt T, Hartig W (1999) Two distinct populations of cholinergic neurons in the septum of raccoon (Procyon lotor): Evidence for a separate subset in the lateral septum. J Comp Neurol 412:112-122.

de Chevigny A, Lemasson M, Saghatelyan A, Sibbe M, Schachner M, Liedo P-M (2006) Delayed onset of odour detection in neonatal mice lacking tenascin-C. Mol Cell Neurosci 32:174-186.

Doetsch F (2003) A niche for adult neural stem cells. Curr Opin Genet Dev 13:543-550.

Doetsch F, Garcia-Verdugo JM, Alvarez-Buylla A (1997) Cellular composition and three-dimensional organization of the subventricular germinal zone in the adult mammalian brain. J Neurosci 17:5046-5061.

Doetsch F, Caille I, Lim DA, Garcia-Verdugo JM, Alvarez-Buylla A (1999a) Subventricular zone astrocytes are neural stem cells in the adult mammalian brain. Cell 97:703-716.

Doetsch F, Garcia-Verdugo JM, Alvarez-Buylla A (1999b) Regeneration of a germinal layer in the adult mammalian brain. Proc Natl Acad Sci USA 96:11619-11624.

Garcion E, Faissner A, ffrench-Constant C (2001) Knockout mice reveal a contribution of the extracellular matrix molecule tenascin- $\mathrm{C}$ to neural precursor proliferation and migration. Development 128:2485-2496.

Garcion E, Halilagic A, Faissner A, ffrench-Constant C (2004) Generation of an environmental niche for neural stem cell development by the extracellular matrix molecule tenascin C. Development 131:3423-3432.

Gates MA, Fillmore H, Steindler DA (1996) Chondroitin sulfate proteoglycan and tenascin in the wounded adult mouse neostriatum in vitro: dopamine neuron attachment and process outgrowth. J Neurosci 16:8005-8018.

Gritti A, Parati EA, Cova L, Frolichsthal P, Galli R, Wanke E, Faravelli L, Morassutti DJ, Roisen F, Nickel DD, Vescovi AL (1996) Multipotential stem cells from the adult mouse brain proliferate and self-renew in response to basic fibroblast growth factor. J Neurosci 16:1091-1100.

Hack MA, Saghatelyan A, de CA, Pfeifer A, shery-Padan R, Lledo PM, Gotz M (2005) Neuronal fate determinants of adult olfactory bulb neurogenesis. Nat Neurosci 8:865-872.

Hartig W, Brauer K, Fritschy J-M, Bruckner G, Bigl V (1995) Regional and cellular expression sites of the alphal subunit of GABA A receptors in the rat basal forebrain: a cytochemical study with glutamic acid decarboxylase, choline acetyltransferase, calcium-binding proteins and nitric oxide synthase as second markers. Brain Res 692:215-226.

Irintchev A, Rollenhagen A, Troncoso E, Kiss JZ, Schachner M (2005) Structural and functional aberrations in the cerebral cortex of tenascin-C deficient mice. Cereb Cortex 15:950-962.

Iseda T, Nishio T, Kawaguchi S, Kawasaki T, Wakisaka S (2003) Spontaneous regeneration of the corticospinal tract after transection in young rats: collagen type IV deposition and astrocytic scar in the lesion site are not the cause but the effect of failure of regeneration. J Comp Neurol 464:343-355.

Johe KK, Hazel TG, Muller T, Dugich-Djordjevic MM, McKay RD (1996) Single factors direct the differentiation of stem cells from the fetal and adult central nervous system. Genes Dev 10:3129-3140.

Jones FS, Jones PL (2000) The tenascin family of ECM glycoproteins: structure, function, and regulation during embryonic development and tissue remodeling. Dev Dyn 218:235-259.

Kerever A, Schnack J, Vellinga D, Ichikawa N, Moon C, Arikawa-Hirasawa E, Efird JT, Mercier F (2007) Novel extracellular matrix structures in the neural stem cell niche capture the neurogenic factor FGF-2 from the extracellular milieu. Stem Cells 25:2146-2157. 
Kosaka K, Toida K, Aika Y, Kosaka T (1998) How simple is the organization of the olfactory glomerulus?: the heterogeneity of so-called periglomerular cells. Neurosci Res 30:101-110.

Laywell ED, Dorries U, Bartsch U, Faissner A, Schachner M, Steindler DA (1992) Enhanced expression of the developmentally regulated extracellular matrix molecule tenascin following adult brain injury. Proc Natl Acad Sci USA 89:2634-2638.

Lim DA, Alvarez-Buylla A (1999) Interaction between astrocytes and adult subventricular zone precursors stimulates neurogenesis. Proc Natl Acad Sci USA 96:7526-7531.

Lois C, Garcia-Verdugo JM, Alvarez-Buylla A (1996) Chain migration of neuronal precursors. Science 271:978-981.

Menn B, Garcia-Verdugo JM, Yaschine C, Gonzalez-Perez O, Rowitch D, Alvarez-Buylla A (2006) Origin of oligodendrocytes in the subventricular zone of the adult brain. J Neurosci 26:7907-7918.

Mercier F, Kitasako JT, Hatton GI (2003) Fractones and other basal laminae in the hypothalamus. J Comp Neurol 455:324-340.

Moore KA, Lemischka IR (2006) Stem cells and their niches. Science 311:1880-1885

Nishio T, Kawaguchi S, Yamamoto M, Iseda T, Kawasaki T, Hase T (2005) Tenascin- $\mathrm{C}$ regulates proliferation and migration of cultured astrocytes in a scratch wound assay. Neuroscience 132:87-102.

Parras CM, Galli R, Britz O, Soares S, Galichet C, Battiste J, Johnson JE,
Nakafuku M, Vescovi A, Guillemot F (2004) Mash1 specifies neurons and oligodendrocytes in the postnatal brain. EMBO J 23:4495-4505.

Peretto P, Giachino C, Aimar P, Fasolo A, Bonfanti L (2005) Chain formation and glial tube assembly in the shift from neonatal to adult subventricular zone of the rodent forebrain. J Comp Neurol 487:407-427.

Rauch U, Zhou XH, Roos G (2005) Extracellular matrix alterations in brains lacking four of its components. Biochem Biophys Res Comm 328:608-617.

Riquelme PA, Drapeau E, Doetsch F (2008) Brain micro-ecologies: neural stem cell niches in the adult mammalian brain. Phil Trans $\mathrm{R}$ Soc B 363:123-137.

Saga Y, Yagi T, Ikawa Y, Sakakura T, Aizawa S (1992) Mice develop normally without tenascin. Genes Dev 6:1821-1831.

Steindler DA, Settles D, Erickson HP, Laywell ED, Yoshiki A, Faissner A, Kusakabe M (1995) Tenascin knockout mice: barrels, boundary molecules, and glial scars. J Neurosci 15:1971-1983.

Thomas LB, Gates MA, Steindler DA (1996) Young neurons from the adult subependymal zone proliferate and migrate along an astrocyte, extracellular matrix-rich pathway. Glia 17:1-14.

von Holst A, Sirko S, Faissner A (2006) The unique 473HDchondroitinsulfate epitope is expressed by radial glia and involved in neural precursor cell proliferation. J Neurosci 26:4082-4094. 